\title{
EDITORIAL
}

\section{Primera Encuesta Nacional de Salud}

En nuestra calidad de formadores e investigadores en Salud Pública, queremos enviar una señal de gran satisfacción por la realización de la Primera Encuesta Nacional de Salud en la población chilena. Esta iniciativa constituye una clara muestra de madurez de nuestro sistema, el cual -a la manera que lo han hecho los países desarrollados-, se adelanta a los problemas y busca conocerlos en su origen. Por cierto, su aparición no es aleatoria sino resultado de un proceso activo de búsqueda y claridad de la información que es propio de organizaciones democráticas y conscientes de sus responsabilidades en el ámbito de salud de la población. En tal sentido, vale la pena explorar la forma en que se desarrollaron los sistemas de información que competen a los intereses de la Salud Pública.

Estos estudios se inician en Chile en 1778, cuando Agustín de Jáuregui dispuso el primer censo abarcando el Obispado de Santiago. Ya en 1843, Manuel Bulnes creó una "Oficina de Estadística" entre cuyas funciones estaba el ordenamiento de las informaciones estadísticas que llegaban de las provincias y parroquias y la preparación del nuevo censo. La ley de censos, dictada el 12 de julio de ese año, estableció el período decenal para la realización de censos de población.

Aparte de continuar esta tradición centenaria, a través de la realización de los Censos Nacionales de Población y Vivienda, el Instituto Nacional de Estadísticas (creado en 1960) es responsable de importantes actividades de empadronamiento como el Censo Agropecuario, la Encuesta Nacional de Empleo, las Estadísticas Vitales (generadas por el Servicio de Registro Civil e Identificación y el Ministerio de Salud) y las Cuentas Nacionales (generadas por el Banco Central).

Un importante actor en el área de formulación del diagnóstico y en la evaluación del impacto de la política social y de los programas que componen el gasto social es la Encuesta de Caracterización Socioeconómica Nacional (CASEN), que ha realizado bianualmente el Ministerio de Planificación y Cooperación (MIDEPLAN) desde 1985 hasta su versión más reciente en 2003.

Entre las actividades del Consejo Nacional para el Control de Estupefacientes (CONACE), se ha destacado la realización de encuestas nacionales bianuales tales como el Estudio Nacional de Drogas en la Población Escolar de Chile de $8^{\circ}$ Básico a $4^{\circ}$ Año de Enseñanza Media, y el estudio Nacional de Drogas en Población General y encuestas focalizadas, por ejemplo, a conductores de locomoción colectiva o consultantes en servicio de urgencia.

De especial relevancia es la actividad del Departamento de Estadística e Información de Salud (DEIS) del MINSAL, que genera o administra diversos sistemas de registros continuos sobre Estadísticas de Población, Estadísticas Vitales, Estadísticas de Morbilidad, de Recursos para la Salud, de atenciones de salud, entre otros. Adicionalmente ha realizado la "Encuesta de Calidad de Vida y Salud, Chile 2000" y la "Encuesta Nacional de Salud, Chile 2003", que marcan un hito en los esfuerzos nacionales orientados a proveer la mejor base a la planificación de las intervenciones en Salud Pública.

La existencia de esta históricamente sólida información estadística, que abarca todas las principales áreas de la actividad nacional, favorece el desarrollo de la ciencia en nuestro país y -particularmente- el referente a la Salud Pública. Plantea, a su vez, 
grandes desafíos a las autoridades responsables por estos registros, encuestas e investigaciones específicas para avanzar en la orientación democrática y, salvo algunos resguardos legales, asegurar el acceso a esta información, obtenida con recursos públicos, a quienes puedan obtener el máximo provecho en beneficio de la comunidad. A los investigadores de todas las áreas relacionadas, el también gran desafío de explotar este capital en forma creativa e intensa, como parte inherente a nuestro actuar académico y teniendo en vista la retroalimentación del sistema y, en última instancia, el bienestar de la comunidad. 